\title{
Tarefa de casa como ação educativa: uma relação entre a escola, $o$ aluno e a família
}

Homework as educational action: a relationship between school, student and family

Tatiane Keila de Moura Sant'Anna Luciana Teles Moura Pirola

Resumo: O artigo exibe parte da pesquisa concretizada no Mestrado Profissional em Ciência, Tecnologia e Educação, da Faculdade Vale do Cricaré - ES, sobre: Tarefa de casa como ação educativa: uma relação entre a escola, o aluno e a família. Justificase este estudo por acreditar na importância da família e escola caminharem juntas em busca de uma educação voltada para o sucesso do aluno na escola. A metodologia empregou pesquisa bibliográfica e de campo. Um roteiro de entrevista foi aplicado a uma professora, aos pais ou responsáveis por alunos e alunos, na perspectiva de identificar a participação da família na vida escolar das crianças. O estudo caracterizase por uma abordagem qualitativa. Após conclusão constatou-se, que a integração entre família e escola pode ser considerada, se não a mais importante, como um dos pontos principais para a melhoria da aprendizagem dos educandos.

Palavras-chave: Tarefa de Casa. Família. Escola. Aprendizagem.

Abstract: The article shows part of the research carried out in the Professional Master's degree in Science, Technology and Education, from Vale do Cricaré College ES, on: Homework as an educational action: a relationship between the school, the student and the family. This study is justified by believing in the importance of the family and school to walk together in search of an education focused on the success of the student in the school. The methodology used bibliographic and field research. An interview script was applied to a teacher, parents or guardians of students and students, in order to identify the participation of the family in the children's school life. The study is characterized by a qualitative approach. After completion, it was found that the integration between family and school can be considered, if not the most important, as one of the main points for improving the learning of students.

Keywords: Homework. Family. School. Learning.

\section{Introdução}

O artigo é pertinente por abordar um tema atual e essencial ao cotidiano escolar. A família e a escola precisam definir seus papéis perante a aprendizagem dos educandos fazendo-se parceiros para o pleno desenvolvimento educacional dos mesmos.

Sabe-se que escola e a família compartilham funções sociais, políticas e educacionais. Ambas são responsáveis pela transmissão e construção do 
conhecimento culturalmente organizado de acordo com as expectativas de cada ambiente, conforme cita Polonia e Dessen, 2005, p. 304:

A família e a escola destacam-se como duas instituições
fundamentais cuja importância só se compara à própria
existência do Estado como fomentador dos processos
evolutivos do ser humano, proporcionando ou inibindo seu
crescimento físico, intelectual e social no ambiente escolar, [...]

Quanto a questão pertinente à aprendizagem a partir da relação família e escola, ocorreu uma pesquisa bibliográfica sobre o tema "tarefa de casa como ação educativa", através das obras de Albertina de Mattos Charin.família e escola; Ana Paula Jardim - relação entre a família e escola; Isabel Cristina Hierro Parolin - Professores Formadores: a relação entre família, a escola e a aprendizagem, dentre outros. Após esse levantamento realizou-se uma entrevista com os alunos, pais e uma professora, onde informações foram registradas. A pesquisa concretizou-se com alunos do $3^{\circ}$ e $4^{a}$ ano (turma multisseriada) com idades entre oito e dez anos. Estiveram envolvidos na pesquisa, os alunos das referidas turmas, pais e educadora, que participaram da entrevista sobre o tema. Deu-se o estudo durante um período do ano letivo em uma escola mantida pelo governo municipal, localizada na zona rural do município de Presidente Kennedy ao sul do Estado do Espírito Santo.

Efetivou-se a pesquisa com intenção de verificação da realização da tarefa de casa e a visão de alunos, pais e a professora escolhida para a pesquisa em relação a sua prática. Foram organizados os dados da pesquisa em forma de texto descritivo e gráficos, para facilitar a visualização dos participantes da mesma e análise pela pesquisadora/entrevistadora.

Os resultados exibidos neste artigo de acordo com as pessoas envolvidas foram realizados durante as entrevistas foram apresentados à "Banca Final" na Instituição "Faculdade Vale do Cricaré" - FVC em São Mateus/ES, como objetivo da mestranda para alcançar o título de "mestre". Sendo que a partir das respostas da entrevista para a realização do produto final, sugeriu-se um guia didático para a família, em uma versão de bolso, abordando a importância da parceria entre escola e família do aluno e algumas orientações sobre tarefa de casa. 
A escola é para a sociedade uma extensão da família (Symanski, 2001, p. 90), onde desenvolvem-se pessoas críticas e conscientes de seus direitos e deveres. Assim, sendo um ambiente conveniente e favorável a todos, constituise num grande desafio para a escola. Diante desse contexto, percebe-se que o papel da escola supera a condição de mera transmissora de conhecimento.

\section{A família é a primeira escola da criança}

Um dos pilares importantes para adentrar na educação escolar é antes de tudo a educação familiar. Saber criticar ou elogiar no momento certo, são princípios eficazes para uma postura correta com poder de respeito contraído através do diálogo.

Isto posto, a escola se apresenta como um lugar em que é possível o convívio com um grupo heterogêneo de crianças matriculadas nos terceiros e quartos anos do Ensino Fundamental no mesmo espaço ou não. É, portanto, o lugar adequado para desenvolver os hábitos de socialização que a vida em comunidade demanda.

Nesse caso, a família é uma das instituições responsáveis pelo processo de socialização das crianças, pois tem em suas mãos o papel de instruir e educar, e ainda é considerada a base na formação do ser humano.

Deste modo, tanto a convivência, quanto o relacionamento familiar são fatores fundamentais para o desenvolvimento individual. Entender o indivíduo como parte de um sistema, com elementos que interagem entre si, influenciando cada parte e sendo por ela influenciado, traz uma luz à compreensão acerca do desenvolvimento humano, contribuindo para a reflexão sobre os contextos familiares e escolares, que tanto podem ser elementos de moderação, inclusão e segurança.

Conforme Charim (2009, p. 25-26), "Não importa de quantos, nem de quais elementos uma família se compõem. Importante é a qualidade dos laços afetivos que mantem a dinâmica familiar". Manter bons laços familiares irá estruturar o desenvolvimento social da criança.

Segundo o Estatuto da Criança e do Adolescente (ECA, 1990) em seu Art. 19 diz: "Toda criança ou adolescente tem direito de ser criado e educado 
no seio de sua família e excepcionalmente em família substituída, assegurada a convivência familiar e comunitária em ambiente livre de entorpecentes".

Toda criança tem o direito a uma família, seja ela substituta ou não, e privá-la desse direito pode ser de encarcerá-la a uma vida de frustrações e perdas irreparáveis. Não importa os componentes desta família como é formada esta composição, pois o objetivo maior é o bom desenvolvimento da criança.

Talvez os possíveis problemas encontrados na escola sejam solucionados junto à família desde que a mesma seja presente na vida escolar desta criança. A falta dos pais na vida educacional de seus filhos nos leva a crer que essa ausência acontece em outros momentos também. Na maioria das vezes as primeiras frustrações de uma criança acontecem dentro do ambiente familiar, sendo mais tarde refletida na sua vida social a fora, a começar pela escola, onde acontecerá sua segunda socialização.

\section{O lugar da escola na vida do aluno}

A escola é uma instituição social relevante na sociedade, pois além de possuir o papel de fornecer preparação intelectual dos alunos, ocorre também, a inserção social. Isso se dá pelo fato da escola ser um importante meio social frequentado pelos indivíduos, depois do âmbito familiar.

Canivez, mostra que a escola passa a ser o espaço social, depois da família:

A escola, de fato, institui a cidadania. É ela o lugar onde as crianças deixam de pertencer exclusivamente à família para integrarem-se numa comunidade mais ampla em que os indivíduos estão reunidos não por vínculos de parentesco ou de afinidade, mas pela obrigação de viver em comum. A escola institui, em outras palavras, a coabitação de seres diferentes sob a autoridade de uma mesma regra. (CANIVEZ, 1991, p. 33)

Entende-se que a escola é um espaço onde os indivíduos começam a ter as relações para além da família, ou seja, passa a conviver com pessoas de diferentes raças, cor, etnia, religião, cultura. 
De acordo com Silva (2009), a educação é um processo pelo qual uma sociedade molda os indivíduos que a constituem, assegurando sua repetição ou continuidade histórica, pois o processo de escolarização dura por toda a vida; mostrando-nos que a sociedade pode modificar de acordo com o seu interesse, visando repassar a seus membros, suas significações, valores, saberes e interpretações do mundo.

Enquanto a educação, enquanto direito garantido a todos, também possui suas leis e diretrizes. O direito a educação, priorizando o seu acesso e a permanência do aluno na escola, tem sido garantido nos aportes legais, na Constituição Federal de 1988, na Lei Federal 8069/90- Estatuto da Criança e do Adolescente- ECA e na Lei de Diretrizes e Bases da Educação Nacional LDB 9.394/96, objetivando a formação do usuário para o exercício da cidadania, preparação para o trabalho, e sua participação social.

Está garantido na Constituição Federal Brasileira, desde 1988, no artigo 205, que diz: "a educação, direito de todos e dever do Estado e da família, será promovida e incentivada com a colaboração da sociedade [...]", sendo assim, todos sem exceção devem ter acesso à educação.

Como consta no Estatuto da Criança e Adolescente:

Art.53. A criança e o adolescente têm direito à educação, visando o pleno desenvolvimento de sua pessoa, preparo para o exercício da cidadania, e qualificação para o trabalho, assegurando-lhes:

I. igualdade de condições para o acesso e permanência na escola;

II. direito de ser respeitado por seus educadores;

III. direito de contestar critérios avaliativos, podendo recorrer às instâncias escolares superiores;

IV. direito de organização e participação em entidades estudantis;

V. acesso à escola pública e gratuita próxima de sua residência. (ECA, 2009)

Para Freitas (2011) cabe à escola formar cidadãos críticos, reflexivos, conscientes de seus direitos e deveres, tornando-se aptos a contribuir para a construção e/ou desconstrução de uma sociedade visando à igualdade e 
justiça. Entretanto, sua função não está apenas em proporcionar a simples transmissão do conhecimento, tem o compromisso social para, além disso. Preocupa-se também em prover a capacidade do aluno de buscar informações segundo as exigências de seu campo profissional ou conforme as necessidades de seu desenvolvimento individual e social.

Ainda afirma a autora, que a escola precisa:

A cada momento fazer o aluno pensar, refletir, analisar, sintetizar, criticar, criar, classificar, tirar conclusões, estabelecer relações, argumentar, avaliar, justificar, etc. Para isto é preciso que os professores trabalhem com metodologias participativas, desafiadoras, problematizando os conteúdos e estimulando o aluno a pensar, a formular hipóteses, a descobrir, a falar, a questionar, a colocar suas opiniões, suas divergências e dúvidas, a trocar informações com o grupo de colegas, defendendo e argumentando seu ponto de vista (FREITAS, 2011, s/p).

\section{Família e escola: uma importante e necessária relação}

A questão da participação dos pais na educação escolar dos filhos é de grande importância, devendo acontecer frequentemente, acompanhando todo o processo educativo. Para que isso aconteça é necessário que a escola e a família estejam em sintonia para exercerem suas influências no desenvolvimento da criança.

A educação é a ação exercida pelas gerações adultas sobre as gerações que não se encontrem ainda preparadas para a vida social; tem por objetivo suscitar e desenvolver, na criança, certo número de estados físicos, intelectuais e morais, reclamados pela sociedade política, no seu conjunto, e pelo meio especial que a criança particularmente se destine. (DURKHEIM, 1978, p. 41)

Assim, essa nova percepção de educação começa a provocar uma nova herança cultural no aluno, onde ele entra em contato com outros sujeitos e começa uma nova forma de socialização.

De acordo com Brandão (1982, p. 12), "a educação existe sob tantas formas e é praticada em situações tão diferentes, que algumas vezes parece ser invisível", desta forma é necessário entender que nestes ambientes a 
educação que a criança está recebendo ultrapassa em muito a formativa, a que está sendo planejada e controlada pelos adultos que a rodeiam.

Sendo assim, cabe à escola evidenciar interesse por tudo o que o aluno já conhece, ou seja, de conhecimento prévio, e também o conhecimento que ele irá adquirir dentro dos muros da escola. Tudo tem o seu devido significado e importância.

Não se pode esquecer que a aprendizagem da criança não acontece apenas em um ambiente, ela está aprendendo em todo momento, ao entrar em contato com outras pessoas e presenciando diversas situações, e são nessas circunstâncias que ela pode aplicar o que aprendeu tanto no ambiente familiar como no ambiente escolar. Desta forma Lacasa aponta que:

A escola não pode esquecer o mundo familiar e, mais especialmente, a história social das famílias, o conteúdo de suas bases de conhecimentos e as metas do ensino de todas as pessoas adultas que participam no processo educacional da criança. (LACASA, 2004, p. 414)

Para que haja uma relação de confiança entre pais e escola, é necessário um trabalho de ensino em conjunto de ambas as partes, familiar e escolar para que a comunicação seja estabelecida de modo eficaz.

E assim, as relações entre a família e a escola apresentam padrões e formas de interação bem peculiares que precisam ser identificados e analisados com o intuito de propiciar uma melhor compreensão não só dos aspectos gerais da integração entre ambos como também daqueles mais peculiares a cada ambiente.

Sendo a família, a base de uma formação completa do indivíduo, tendo papel decisivo na formação de caráter, deve ter participação direta na educação das crianças. É fundamental que aconteça essa parceria entre escola e família, e que juntos possam alcançar o objetivo em comum, de formar cidadãos que saibam como viverem no mundo atual.

Conforme Jardim, (2006) a relação escola e família vêm sendo muito discutida nos últimos tempos. A grande dúvida é saber os limites entre os deveres da família e os da escola. Como se sabe, não é a escola e sim a família que proporciona as primeiras experiências educacionais à criança. 
Nas escritas de Sandi,

A família é o berço da formação de regras, princípios e valores, outras instituições assim como a escola, possuem também papel muito importante nesta formação moral, a escola se organizando de forma democrática, oportunizando uma vivência cidadã. Dessa forma, promovem o nascimento crescimento do respeito mútuo e o desenvolvimento da autonomia, ingrediente para formação moral. (SANDI, 2008, p. 34).

Conforme descrito nos itens anteriores às mudanças socioeconômicas definiram de forma decisiva a relação entre essas duas instituições. Jardim observa que:

Conforme o modelo Piagetiano, o vínculo escola-família prevê o respeito mútuo, o que significa tornar paralelos os papéis de pais e professores, para que os pais garantam as possibilidades de explorarem suas opiniões, ouvirem os professores sem receio de serem avaliados, criticados, trocarem pontos de vista. (JARDIM, 2006, p. 41)

De acordo com Regis de Morais (1989), para que aconteça o aprendizado é preciso uma parceria entre o educador, uma participação efetiva das famílias na vida escolar da criança, "o ensina-te e ensinando, respeitando os limites de cada um e sua privacidade", pois o mundo, a sociedade, deixam marcas e aprendizados. É preciso a participação da família nesse aprendizado, a qual já se deu início a socialização.

Parolin destaca:

Que o papel da família na formação e nas aprendizagens das crianças e jovens é ímpar. Nenhuma escola por melhor que seja, consegue substituir a família. Por outro lado, destaco também que a função de escola na vida da criança é igualmente ímpar. Mesmo que as famílias se esmerem em serem educadoras, o aspecto socializador do conhecimento e das relações não é adequadamente contemplado em ambientes domésticos. (PAROLIN, 2008, p. 1)

De uma maneira geral, sobre o fundamental e insubstituível papel da família na educação da criança, afirma Nérici (1972, p. 12) "A educação deve orientar a formação do homem para ele poder ser o que é da melhor forma possível". 
Percebe-se assim, que a ação educativa tem influência da família. Essa influência, no entanto, é básica e fundamental no processo de educar a criança, nenhuma outra instituição possui condições de substituir.

Deste modo, os professores que sempre se colocaram em suas salas de aula, como meros transmissores de seus conhecimentos, hoje deparam com uma realidade onde apenas transmitir tais conhecimentos não basta, é preciso ir além das salas de aulas e em muitos casos fazer o papel dos familiares, na transmissão de valores e princípios, o que faz do educar realmente, mais que um mero ganha pão, mas um ato de amor.

A escola não deve ser só um lugar de aprendizagem, mas também um campo de ação no qual haverá continuidade da vida afetiva, desempenhando o papel de parceira na formação de um indivíduo inteiro e sadio. É na escola que deve se conscientizar a respeito dos problemas do planeta: destruição do meio ambiente, desvalorização de grupos menos favorecidos economicamente, etc. Deve-se falar sobre amizade, sobre a importância do grupo social, sobre questões afetivas (SUTTER, 2007, p. 1).

Nesse sentido, a escola contemporânea tem funções que a obriga, ir além das salas de aula, ter contato com a realidade de seus alunos e enxergálos de maneira afetuosa, não apenas como meros números de certa estatística, mas como indivíduos que necessitam de seu apoio.

\section{Tarefa de casa: uma reflexão necessária à aprendizagem}

É separar aluno/filho, por isto, quanto maior o fortalecimento dessa relação família-escola tanto melhor será o desempenho escolar do filho/educando. Nesse sentido, é importante que elas saibam aproveitar os benefícios desse estreitamento de relações, pois isto irá resultar em princípios facilitadores da aprendizagem e formação social da criança. É o que se pode observar nas palavras de Parolin,

Tanto a família quanto a escola desejam a mesma coisa: preparar as crianças para o mundo; no entanto, a família tem suas particularidades que a diferenciam da escola, e suas necessidades que a aproximam dessa mesma instituição. A escola tem sua metodologia e filosofia para educar crianças, no 
entanto ela necessita da família para concretizar o seu projeto educativo. (PAROLIN, 2003, p. 99)

Considerando que o ser humano aprende o tempo todo, nas mais distintas instâncias que a vida lhe apresenta, o papel familiar é fundamental, pois é ela que tem em suas mãos a responsabilidade de construir o caminho que seu filho irá percorrer. Porém, a escola enquanto instituição formadora que completa a família tem o direito e o dever de fazer essa parceria salutar para que ambas venham dar ao ser humano atual uma formação digna para atuar na sociedade como indivíduo social e preparado para transformá-la.

Dessa forma, é preciso entender que, a escola avalia no desempenho do aluno seu conhecimento intelectual e cultural, mas não isenta a família de responsabilidades, como complementa a Constituição em seu Capítulo III, Seção I, da Educação, Art. 205:

A educação, direito de todos e dever do Estado e da Família,
será promovida e incentivada com a colaboração da sociedade,
visando ao pleno desenvolvimento da pessoa, seu preparo
para o exercício da cidadania e sua qualificação para o
trabalho (BRASIL, 1988).

Diante do exposto a escola não deve apenas visar à construção do conhecimento, mas a formação de valores e atitudes do educando.

Com a participação da família constrói-se a base para qualquer ser humano, não fazendo referência somente à família com laços sanguíneos, mas também as famílias construídas através de laços afetivos.

É neste contexto, que a escola assume papel essencial, pois pode intensificar ações que mobilizem a participação da família no processo de formação de conceitos e referências que irão proporcionar vínculos. Com isso, pode-se conceituar a escola como uma instituição social que se caracteriza como um local de trabalho coletivo voltado para a formação das jovens gerações.

No momento da tarefa de casa os entrevistados são envolvidos nessa atividade, pois a criança busca uma solução para resolver e concretizar o compromisso que foi firmado com o professor. Porém a tarefa de casa tem sido objeto de preocupação e de desentendimento entre a família e a escola. Para 
melhor compreensão, o desencontro acontece entre professores e alunos, entre alunos e seus pais e entre pais e professores.

Eis que o professor deve ter o mesmo compromisso educacional com o aluno em sala de aula, e com a tarefa de casa, pois é o momento que ele não se faz presente com o mesmo e a tarefa de casa é ou deve ser a continuação do conteúdo trabalhado em sala de aula, ou seja, é a complementação do conteúdo estudado, como Parolin descreve que:

O professor quando encaminha uma tarefa de casa, deve ter por objetivo exercitar algo que já foi trabalhado em sala de aula; disparar temas que serão trabalhados nas próximas aulas; avaliar as aprendizagens que seu aluno está construindo e, como decorrência, avaliar a maturidade e a autonomia de seu aluno. (PAROLIN, 2010, p. 48)

Quando um aluno apresenta uma tarefa realizada por ele em casa, para seu professor, ou deixa de apresentá-la, a sua avaliação quanto o fazer ou não fazer se dará não apenas no que conseguiu desenvolver sob a ótica das habilidades, mas todo entorno a que compõe uma tarefa, tais como, compromisso, discernimento, adequação de resposta, entre outros aspectos. $O$ resultado final é considerado, porém o processo em que a tarefa foi executada é igualmente importante.

Vale também afirmar, que o aluno pode apresentar uma tarefa incompleta ou, até mesmo incorreta e demonstrar esforço, comprometimento e trabalho, objetivando o cumprimento da mesma, pois errar faz parte do processo de aprendizagem, o professor pode identificar falhas e reforçar 0 conteúdo nos pontos necessários, individualmente ou coletivamente, caso julgue que a dúvida de um aluno seja de vários também.

Por esse motivo, a família deve participar ativamente da vida escolar de seu filho e um aspecto que se tem discutido entre escola, família e professores são as tarefas solicitadas para que se realizem em casa, pois na maioria das vezes os alunos não as realizam.

Fernandes reforça que:

Os pais são os responsáveis legais e morais pela educação de seus filhos. A educação escolar não os exime desta responsabilidade, sendo inegável a importância da participação 
dos mesmos. Porém é difícil definir o papel que cabe aos pais assim como distinguir os temas que envolvem seu papel complementar, mas, sociologicamente são os primeiros a iniciar a socialização da criança. (FERNANDES, 2006, p. 31)

\section{Resultados}

A entrevista com a professora foi voltada para identificar aspectos que o professor insere na tarefa de casa que requerem a participação da família. Constatou-se que a professora tem o hábito de passar tarefa de casa pelo menos três vezes por semana e afirma que esta é mais uma ferramenta utilizada na fixação dos conteúdos trabalhados em sua sala de aula, além de colaborar com a complementação da aprendizagem. Ela ainda enfatizou que a tarefa de casa deve ser planejada, organizada, acompanhada por ela e pela pedagoga e consequentemente pela família e cobrada todas as vezes que for solicitada ao aluno, caso contrário, ele não assume compromisso e responsabilidade em fazê-las de maneira que venha garantir a revisão do que foi estudado em sala de aula.

Diante do trabalho da professora, percebe-se que ela busca nos plantões pedagógicos, reuniões de pais individuais ou coletivas, datas comemorativas e outros encontros da escola com a família, uma forma de mostrar aos pais ou responsáveis que ela e a escola focada nos alunos/filhos procuram examinar a prática pedagógica para torná-los cidadãos críticos e reflexivos sobre o aprendizado de qualidade. Bem como acontece antes com os alunos em sala de aula.

Para responder o objetivo da entrevista com os pais ou responsáveis, ou seja, investigar a relação família e escola na realização da tarefa de casa como promoção da aprendizagem da criança, Carvalho (2004) entende que como parte integrante do processo ensino-aprendizagem, o dever de casa não apenas afeta o seu planejamento e implementação e, portanto, o trabalho docente, como também afeta a vida dos estudantes fora da escola e em sua rotina familiar, pois supõe a conexão entre as atividades de sala e de sua casa em uma estrutura doméstica adequada apoiando as atividades escolares. 
Dos dezesseis pais ou responsáveis que foram nomeados cada um pela letra do alfabeto na sequência de "A à P", quatorze disseram que a tarefa de casa é muito importante para o desenvolvimento escolar do filho e que gostam de ver os filhos reforçando o que aprenderam na escola em seu ambiente familiar. Disse o responsável "E" que considera importante a atividade, porém não gosta que a filha leva tarefa para casa, pois na maioria das vezes não tem tempo para ajudá-la. Já o responsável "N" disse que não é preciso mandar tarefa de casa, uma vez que lugar de estudar é na escola e estudar o dia inteiro deixa a criança cansada e sem vontade de ir para escola no dia seguinte. Sendo assim, não é preciso solicitar o exercício.

Em relação à pergunta: Como você avalia a aprendizagem de seus filhos através da tarefa de casa?

Os responsáveis " $\mathrm{E}$ " e " $\mathrm{N}$ " mesmo não considerando a tarefa de casa como importante, ressaltaram que deveria ser para ver a dificuldade que os filhos estão tendo com a matéria que esta sendo dada pela professora.

Quatro deles, "C", "G", "J" e "O" de um modo geral identificaram com a tarefa de casa o nível de conhecimento de seus filhos, relatou ainda o responsável "G" que existem conteúdos que o filho tem mais facilidade e outros que ele precisa ajudar.

Os demais responsáveis deixaram claro que observam a autonomia e a responsabilidade dos filhos com o compromisso de fazer a tarefa de casa.

Prosseguindo para outra pergunta: Você disponibiliza tempo e lugar adequado para seu filho fazer a tarefa de casa?

Mesmo sabendo da importância da tarefa de casa e concentração para realizá-la, os responsáveis " $E$ ", "J" e "N" responderam que não ajudam os filhos que somente às vezes disponibiliza tempo e lugar adequado. Os demais responsáveis se preocupam com um lugar mais calmo para facilitar a concentração para realizar a tarefa mais rápida e assim ajudar com os afazeres de casa. Complementando suas respostas, os responsáveis "D", "K", "M" e "P" disseram que os filhos também ajudam a lavar louça, arrumar casa, varrer um quintal, coisas que não venham atrapalhar na escola. $O$ responsável " $F$ " disse 
que aprender na escola é importante, mas aprender para a vida também é primordial.

Finalizando com as perguntas: No dia a dia, enquanto pais ou responsáveis podem dizer que a tarefa de casa é algo?

Bom, necessário, importante, aprendizado, compromisso, responsabilidade, foram às respostas dadas por quatorze responsáveis. Completando, o responsável "B" disse que é um bom momento para acompanhar mais de perto o que a filha está aprendendo na escola. Já o responsável "K" disse que além de acompanhar o que o filho está estudando na escola, também observa se a professora está dando sequência ao conteúdo e que gosta de acompanhar bem de perto. Apenas dois responsáveis, como era previsível, "E" e "N" falaram que é difícil conciliar o trabalho fora de casa, tantas obrigações em casa e a vida escolar dos filhos, por isso acabam deixando essa obrigação de ensinar para escola.

É possível visualizar através das respostas dos responsáveis pelos alunos da turma multisseriada $\left(3^{\circ}\right.$ e $4^{\circ}$ Ano) que a maioria deles se preocupa com o desenvolvimento escolar dos filhos quando se trata da tarefa de casa.

De um modo geral, entre os pais, a tarefa é vista como atividade capaz de melhorar o nível de aprendizagem dos filhos, o que sem dúvida, é fator positivo e está de acordo com os pressupostos desta pesquisa. Entretanto, alguns ainda não conseguem entender o seu papel na vida escolar do filho, deixando este compromisso por conta da escola.

Para finalizar a pesquisa sobre o tema "tarefa de casa", os alunos entrevistados receberam um número para identificação. Os alunos do $3^{\circ}$ Ano foram chamados de "1 à 7 " e os do $4^{\circ}$ Ano de "8 à 16". Mesmo sendo de etapas diferentes, deve-se lembrar que a professora é a mesma, pois trabalha com turma multisseriada.

Uma das perguntas se refere a: Que tipo de tarefa de casa você gosta de fazer?

O aluno "12" representado no gráfico abaixo como $6 \%$ da turma, falou que gosta de pesquisas e interpretações de texto, por serem desafiadores. Ele gosta de coisa nova que vai fazê-lo aprender mais. Três alunos "5", "9" e "14", 
representando $19 \%$ no gráfico dois da turma responderam que preferem tarefa de casa com exercícios de completar ou responder. Doze alunos "1", "2", "3", "6", “7”, "8”, "10", “11", "13" e "15" que somam no gráfico analisado, 75\% disseram que gostam de todo tipo de tarefa de casa. O aluno "4" detalhou em sua resposta que não gosta de fazer sempre a mesma coisa, por isso gosta que a professora passe um tipo de exercício diferente do outro. Finalizando, aluno "16" disse que, já que tem que fazer, que seja pelo menos diferente do que faz na escola. Os percentuais mencionados podem ser vistos no Gráfico 1:

Gráfico 1 - Que tipo de tarefa de casa você gosta de fazer?

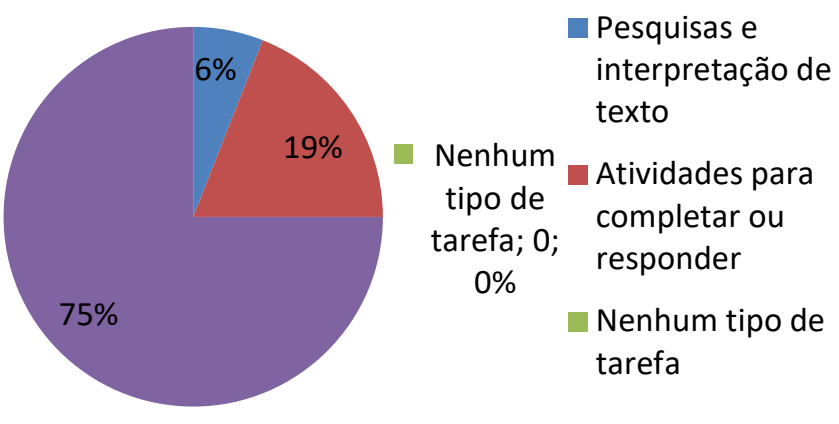

Fonte: Organizado pela pesquisadora com base nos dados da pesquisa.

A outra pergunta: Você pede ajuda aos seus pais ou outras pessoas para fazer a tarefa de casa?

O aluno "14" que representado no gráfico abaixo 4\% dos entrevistados, falou que sempre pede ajuda, mas não é sempre que consegue, porque às vezes na casa dele as pessoas não sabem fazer aquele exercício que a tia passou. Continuando, aluno "12" que soma mais $4 \%$ dos alunos no gráfico analisado, disse que só pede ajuda quando a professora fala que tem que ter a participação da família. Seis alunos: "1", “4", “7”, "8", "11" e "16" que representam $42 \%$ do total no gráfico, afirmam que só pedem ajuda quando não entende direito o que a professora está pedindo. E como a resposta "às vezes", os demais oito alunos "2", “3", “5”, “6”, "9", “10", "13" e “15" responderam esta terceira pergunta da entrevista que representam $50 \%$ dos entrevistados e que podem ser visualizados logo a seguir no Gráfico 2. 
Gráfico 2 - Você pede ajuda aos seus pais ou outras pessoas para fazer a tarefa de casa?

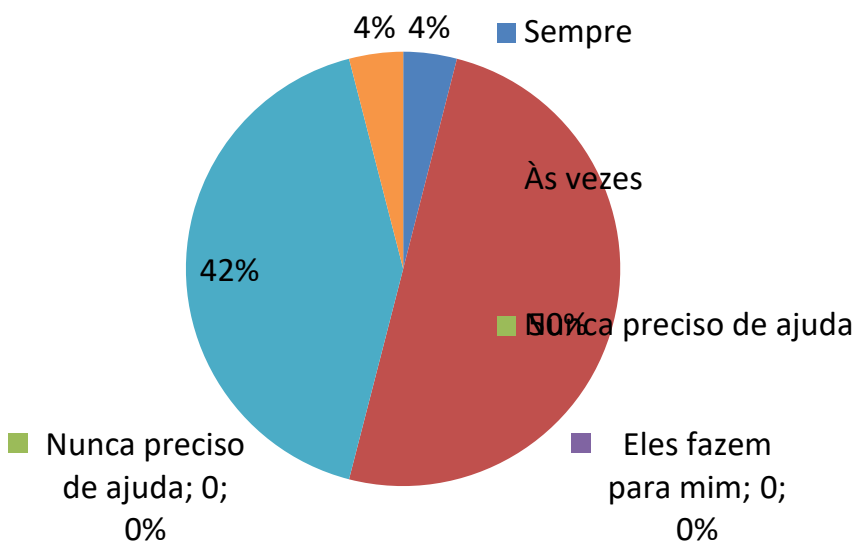

Fonte: Organizado pela pesquisadora com base nos dados da pesquisa.

Ao analisar as respostas dadas nas entrevistas de forma geral (pais ou responsáveis, alunos e professora), constatou-se que todos valorizam a tarefa de casa como estímulo a aprendizagem, e que entendem que a atividade é um recurso fundamental para que a criança complemente o que aprendeu na escola. Também desenvolve senso de autonomia e independência, pois o professor não está presente para ensiná-la.

A escola demonstrará para os pais e ou responsáveis pelos estudantes que o momento da tarefa de casa deverá ser aproveitado como uma aproximação família e escola, com a família dedicando um tempo para conversar sobre os estudos e auxiliando-os no que for preciso. Desta forma eles participam da educação dos filhos/alunos e despertam neles competências e habilidades, estimulando a criatividade e a imaginação.

\section{Conclusão}

Este artigo trouxe à tona questões e reflexões importantes em relação ao processo ensino aprendizagem particularmente sobre detalhes da prática da tarefa de casa e a relação família e escola. Dessa forma foi possível compreender com mais clareza a função de cada uma e suas perspectivas, uma vez que, as instituições familiares e escolares são referências que juntas dão sustentação ao bom desenvolvimento dos filhos/alunos. 
Isto posto, a família espera uma abertura maior por parte da escola a fim de um contato mais frequente. Para isso, é necessário que a escola intensifique e garanta sua permanência no processo por meio de reuniões mais interessantes e motivadoras. Pois, independente de qualquer motivo, a escola tem a função de assumir a responsabilidade sobre a educação da criança, responsabilidade essa que é ou deveria ser natural da família.

É adequado que ambas as partes tendem a colaborar para o equilíbrio no desempenho escolar dos alunos. Sendo necessária essa cooperação efetiva entre as instituições, e quanto mais efetiva ela for, mais significativo será o desenvolvimento dos filhos/educandos.

Convém à escola, a responsabilidade de incentivar e criar oportunidades para que a família se sinta confortável para ter uma participação mais determinante na vida escolar do aluno. Para isso, é preciso conhecer os pais, a fim de saber com quem irá construir relações. Deverá ainda levar em consideração a necessidade e disponibilidade da comunidade que está ao seu redor.

Com relação aos espaços de discussão entre a família e a escola, estes devem ser sempre prezados para que haja qualidade durante os encontros entre professora, pais, alunos e também demais funcionários, para que todos se comprometam em construir uma participação positiva com o proposito de promover uma escola de qualidade de ensino e, com isso proporcionar um melhor desempenho dos alunos.

Contracenando com esta harmonia de relações, entende-se que a atividade de casa trazida da escola, deve ser algo planejado, adequado, onde envolve atividades criativas que levem 0 aluno a raciocinar, a construir conceitos ou reforçar o que foi apresentado em sala de aula, por meio de pesquisa onde ele possua autonomia, mesmo que sob orientação, um incentivo e o interesse da família é de extrema importância e certamente estará contribuindo com sua formação crítica e criativa.

Acredita-se, que a participação da família na escola regularmente, seja uma necessidade contemporânea, almejada por todos que integram o corpo 
docente em uma escola, independente da modalidade de ensino, série ou turma.

Ao longo da construção desta pesquisa foi trilhado um caminho que proporcionou a reflexão sobre a importância da família na execução da tarefa de casa como meio de ação educativa. É clara a importância da participação dos pais neste contexto para o desenvolvimento da criança. Faz-se necessário olhar a escola, não como um ambiente educativo, mas como um espaço importante para o aprofundamento do processo de socialização das relações entre pais, alunos e professores. Sabe-se que não é fácil essa tarefa, pois não se trata só de informações, é indispensável orientar, apontar, compreender e intervir, e todos precisam estar preparados e focados no mesmo objetivo.

Portanto, após as análises pode-se afirmar que quando a criança tem o apoio familiar, ao chegar à instituição escolar, já sabe como situar-se diante dos demais e seu aprendizado é distinto dos outros educandos cuja família não oferece tal apoio, ou seja, que às vezes não tem muito a presença familiar nas suas tarefas escolares.

Cabe, por fim, ressaltar que não se esgota todas as possibilidades de análise dos benefícios da tarefa de casa. Sendo assim, a delimitação desse recorte revelou temas que merecem aprofundamento em outros estudos, como por exemplo, a tarefa de casa como momento especial, como incentivar os alunos na execução e tarefa de casa como estímulo a aprendizagem ..., alguns deles elencados como sugestões para trabalhos futuros.

\section{Referências}

BRANDÃO, Carlos Rodrigues. O que é educação? São Paulo: Brasiliense, 1982. (Coleção Primeiros Passos).

BRASIL. Estatuto da criança e do adolescente (1990). 4. ed. Brasília: Câmara dos Deputados, Coordenação de Publicação, 2003.

. Constituição Federal da República Federativa do Brasil (1988). Disponível em: <https://www.direitonet.com.br/artigos/exibir/479/Educacao-naConstituicao-de-1988-O-artigo-205>. Acesso em: 10 jan. 2020

Diretrizes e Bases da Educação Nacional. Lei $n^{\circ}$ 9.394. Diário Oficial da União, Brasília, 1996. 
CANIVEZ, Patrice. Educar o cidadão? Campinas: Papirus, 1991.

CHARIM, Albertina de Mattos. Família e escola: a arte de aprender para ensinar. Rio de Janeiro: Wak editora, 2009.

DURKHEIM, Émile. Educação e sociologia. 11. ed. São Paulo: Melhoramentos, 1978.

FERNANDES, Jussara. A relação escola e família no ensino fundamental da rede privada na perspectiva do coordenador pedagógico. 2006 . $88 \mathrm{f}$. Dissertação (Mestrado em Psicologia da Educação) - Pontifícia Universidade Católica de São Paulo, São Paulo, 2006. Disponível em: $<$ https://sapientia.pucsp.br/bitstream/handle/16270/1/PED\%20-

\%20Jussara\%20Fernandes.pdf>. Acesso em: 5 abr. 2020.

JARDIM, Ana Paula. Relação entre família e escola: proposta de ação no processo ensino aprendizagem. Presidente Prudente: Unoeste, 2006.

LACASA, P. Ambiente familiar e educação escolar: A interseção de dois cenários educacionais. Em C. Cool, A. Marchesi, \& J. Palacios (Orgs.), Desenvolvimento psicológico (pp. 403- 419). Porto alegre: Artmed. 2004.

MORAIS, Regis de. Cultura Brasileira e Educação. Campinas, São Paulo, Papirus, 1989.

NÉRICI, Imídeo Giuseppe. Lar, escola e educação. São Paulo: Atlas, 1972.

PAROLIN, Isabel Cristina Hierro. Professores formadores: a relação entre família, a escola e a aprendizagem. São José dos Campos: Pulso Editorial, 2010.

Positivo, 2008.

Relação Família e Escola: Revista atividades e experiências.

As dificuldades de aprendizagem e as relações familiares. Livro da $5^{a}$ Jornada de Educação do Norte e Nordeste.

Fortaleza, 2003.

POLONIA, Ana da Costa; DESSEN, Maria Auxiliadora. Em busca de uma compreensão das relações entre família e escola: relações família-escola. Psicologia Escolar e Educacional, p.303-312, 2005. Disponível em: <http://www.scielo.br/pdf/pee/v9n2/v9n2a12.pdf>. Acesso em: 10 set. 2019.

SANDI, Acedriana Vicente. Família berço da formação de regras, princípios e valores. Edição Especial Família. Curitiba: Editora Positivo, n. 5, 2008.

SARRAMONA, Jaume. Educação na Família e na escola: o que é, como se faz. São Paulo: Editora Loyola, 2002.

SILVA, Joelma Oliveira da; RISTUM, Marilena. A violência escolar no contexto de privação de liberdade. Psicol. Cienc. Prof., Brasília, v. 30, n. 2, 2009. 
Disponivel em: $\quad$ <http://www.scielo.br/scielo.php?pid=S141498932010000200002\&script=sci_abstract\&tlng=pt>. Acesso em: 22 out. 2019.

SYMANSKI, Heloisa. A relação família/escola: desafios e perspectivas. Brasília: Plano, 2001.

SUTTER, Graziela. Refletindo sobre a relação família escola, 2007. Disponível em: <http://www.webartigos.com/artigos/refletindo-sobre-a-relacaofamilia escola/926/>. Acesso em: 23 nov. 2019.

\section{Sobre os Autores}

\section{Tatiane Keila de Moura Sant'Anna}

tatianesantanna@globomail.com

Mestre em Educação pela Faculdade Vale do Cricaré - Campus São Mateus/ES, especialista em Psicopedagogia - Ferlagos, especialista em Educação Inclusiva e Diversidade - ISECUB, especialista em Gestão Educacional Integrada: Administração, Supervisão, Orientação e Inspeção ISEAC, graduada em Licenciatura Plena em Pedagogia - Habilitação: Magistério das Matérias Pedagógicas do $2^{\circ}$ Grau e Supervisão Escolar de $1^{\circ} \mathrm{e}$ $2^{\circ}$ Graus. Pedagoga Estatutária da Prefeitura Municipal de Marataízes/ES desde 2008 e Professora do Ensino Fundamental Anos Iniciais em Designação Temporária há 24 anos.

\section{Luciana Teles Moura Pirola}

lucianatmoura@gmail.com

Doutora e Mestre em Psicologia pela Universidade Federal do Espírito Santo, especialista em Educação e Publicitária. Atualmente trabalha com pesquisa de processos de ensino e relacionamentos interpessoais e orientação de pesquisa a mestrandos da Faculdade Vale do Cricaré. 